\title{
NOTAS SOBRE EL ARRENDAMIENTO DE LA ALCABALA A TRAVÉS DE LOS CUADERNOS DE 1462 Y 1484
}

\author{
Miguel ANGel Solinís Estallo
}

\author{
SUMARIO
}

Introducción. - 1. Individualización de la renta. - 2. Estimación de su valor. - 3. Especificar los situados que sobre ésta se libran. - 4. Eliminar las posibles alteraciones sobre el valor de la renta.

\section{INTRODUCCIÓN}

El presente trabajo pretende estudiar la gestión tributaria de la Hacienda Regia en el último tercio del siglo XV a través de su impuesto más significativo, la alcabala. En concreto, me centraré en un aspecto de esta gestión, el que corresponde a la determinación del precio de la renta para su ulterior remate en almoneda pública, singularizando el estudio en los Cuadernos de Alcabala de 1462 y 1484, promulgados por Enrique IV y los Reyes Católicos respectivamente '. El interés del segundo reside, para Moxó, en su extensión y sistematización, constituyendo un punto final en la legislación real sobre las alcabalas ${ }^{2}$. El Cuaderno de 1462 me servirá como referencia inmediata en el tiempo, permitiéndonos observar la clara homogeneidad en política tributaria de los últimos monarcas Trastámaras. Evito el estudio del Cuaderno de 1491 por dos motivos: primeramente, por derivar toda su legislación del de 1484, represen-

1 Para el Cuaderno de 1462 utilizo la transcripción realizada por Moxó y aparecida en el «AHDE, 1969, pp. 383-450. Para el Cuaderno de 1484, Archivo General de Simancas, Sección de Diversos de Castilla. Leg. 4, F' 114 (ms.).

- Salvador de Moxó, Los cuadernos de alcabalas. Origenes de la legislación tributaria cassellana, "AHDE» (Madrid, 1969), pp. 327. 
tando por lo tanto una continuidad con respecto a éste, y en segundo lugar por su copilación en el Libro III de la Nueva Recopilación, lo que hace de éste un documento ampliamente conocido y manejado. Asímismo, por la estrecha relación que se establece entre los Cuadernos y las Cortes, me ha parecido oportuno estudiar los aspectos fiscales que aparecen referidos en las Cortes de Madrigal de 1476 y de Toledo de 1480, Cortes a las que el cuaderno de 1484 hace mención en múltiples ocasiones.

El interés de mi estudio reside en el hecho de que la gestión tributaria de la alcabala manifiesta la capacidad fiscal de la Hacienda Regia a dos niveles. Primero, al revelar su capacidad obligacional en matera contributiva, esto es, la relación que se establece entre la Monarquía -sujeto activo de la imposición- y "las gentes del reino" -sujeto pasivo- que la hace efectiva. Y en un segundo nivel al mostrar los mecanismos que, a través de esta gestión, mantiene la monarquía para rentabilizar en términos de interés económico el tipo de gestión efectuada.

En el primer nivel habrá que señalar como la Hacienda Regia de finales del siglo XV mantiene aún ese carácter de institución administrativa con facultades limitadas, que requería de la subrogación de la recaudación de sus ingresos -imprescriptibles- para hacer efectiva la actividad fiscal de la monarquía, dada su incapacidad de gestión recaudatoria directa (debido a la deficiente articulación de su administración tributaria), por lo que su poder financiero se encuentra limitado ?.

Y es dentro de este esquema administrativo donde la alcabala adquiere pleno significado como impuesto de carácter indirecto, y no tanto desde un punto de vista económico, al tener como objeto el consumo, sino desde una percepción jurídica al obtener la Hacienda Regia las cuotas tributarias de personas distintas de aquellas a las que la ley grava, esto es, a través del sistema de arrendamiento, el cual, a finales de este siglo, permite observar con nitidez la doble titularidad del poder financiero ${ }^{4}$ :

- El Rey, sujeto activo de la imposición, quien desde las Cortes y a través

' Limitación que ARTOLA prolonga hasta el siglo XVIII. La Hacienda del Antiguo Régimen, Alianza Universidad, Textos. Madrid, 1982, p. 27. De igual forma, para LADERO QUESADA usi el monarca aceptaba el sistema de arrendamiento se debía a que cualquier otra manera de promover la gestión de las rentas hubiera sido más costosa para él, o menos eficaz, o simplemente imposible, por no contar con los medios financieros precisos para ponerla en marchan. La Hacienda Real de Castilla en el siglo XV Ed. Universidad de la Laguna, 1973, p. 22.

' Para los aspectos finacieros y tributarios ver: Fernando SAINZ DE BUJANDA, Lecciones de Derecho Financiero, Ed. Universidad Complutense. Facultad de Derecho. Sección de Publicaciones. Madrid, 1982. Juan Castillo Castillo y Restituto Sierra Bravo, Procedimiento Recaudatorio. Reglamento General de Recaudación en «Revista de Derecho Fianciero y de Hacienda Pública. Comentario a las leyes Tributarias y Financieras» Tomo XVI. 
de los Cuadernos de Alcabala, crea derecho tributario. No olvidemos en este sentido que las Cortes tiene un rango jurídico superior a los Cuadernos, y por tanto estos recogen normas tributarias redactadas previamente en los Cuadernos de Cortes. (En este sentido no coincido en la percepción señalada por Salvador de Moxó a la hora de indicar como la relación que se establece entre Cortes y Cuadernos de Alcabala queda limitada a la circunstancia de su elaboración, esto es, su redacción respondería a una petición expresada previamente en Cortes, y así la redacción del Cuaderno de 1377 respondería a un deseo allí expresado y explicitado en el encabezamiento de dicho Cuaderno. Como ya veremos la relación que se establece, por ejemplo, entre las Cortes de 1476 y 1480 con el Cuaderno de 1484 es muy estrecha en lo referente a su articulado aunque en ningún momento se indica que su redacción responda a una petición expresada en Cortes ').

- El arrendador, sujeto activo de la relación tributaria, titular de un derecho que le faculta para hacer efectiva una prestación tributaria del contribuyente. Su actuación y los objetivos del sistema de arrendamiento del servicio recaudatorio vendrán claramente explicitados en la redacción de ambos cuadernos.

No obstante, si en ese primer nivel referido a la recaudación tributaria la capacidad financiera queda mermada, tras el cotejo de las fuentes arriba señaladas podemos observar como el objetivo real al delegar mediante el arrendamiento su potestad recaudatoria no será únicamente el de hacer efectiva esta capacidad, sino, sobre todo, obtener un incremento en el haber de la Hacienda Regia sobre la base de rentabilizar en la mayor medida posible esta renta, con lo que su capacidad financiera queda garantizada. Es decir, dada la incapacidad observada para la última mitad del siglo XV para hacer confluir ambos niveles, la corona intentó rentabilizar en términos de interés económico la pérdida de cierta capacidad administrativa. Y es por esta circunstancia por la que centraré el interés de este trabajo en este último aspecto.

Ya en la primera disposición del cuaderno de 1462 se señala con nitidez esta pretensión: (refiriéndose a los contadores mayores) «e las arrendades e remates -las rentas de las alcabalas, tercias y 'otros pechos y derechos'- en quien mas por ellas diere» ${ }^{6}$. En este sentido, el Tesoro Regio obtiene por remate un precio por la renta alcabalatoria a cambio de ceder transitoriamente

' Es más, llega a indicar como esta circunstancia no hace sino mostrar «la creciente independencia y firmeza del Poder Real frente a las Cortes", imponiéndose la Monarquía en el plano administrativo a «los estamentos colegiados sobre los que ganaba atribuciones a través de sus órganos de gobierno o consolidaba sus tradicionales facultades legislativas». (Los Cuadernos de Alcabalas, p. 325).

- Cuaderno de 1462, disposición 1ª, p. 383. 
su papel como titular del crédito a un arrendador. Precio que se entiende suficiente frente al rendimiento de la propia renta. La recaudación tributaria, por tanto, se subroga, y ésta se verifica cuatrimestralmente ( «la terçia parte en fyn del mes de mayo e la otra terçia parte en fyn del mes de septiembre de cada un año e la otra terçia parte en fyn del mes de enero del año seguyente" '), debiendo ajustarse la percepción de las cuotas tributarias correspondientes con el precio fijado. Los superavits irán en beneficio del arrendador, siendo ésta la situación ideal, pero las posibles quiebras irán en perjuicio de la Hacienda Regia por cuanto altera las previsiones establecidas en la gestión del gasto público ". Este temor se intenta soslayar desde los propios cuadernos mediante dos mecanismos:

- El establecimiento de fianzas que garantizan el ingreso tributario. En este sentido la casuística referida en ambos cuadernos es muy prolija.

- Se impide explícitamente cualquier descuento sobre las alcabalas, o si se quiere sobre la alicuota establecida: «aunque dapno o mengua o pérdida venga en las dichas rentas por fuego o guerra o por agua o piedra o niebla, o por otro cabso fortuyto, qualquiera que sea o ser pueda mayor o menor o ygual destos" ". No olvidemos que se cede la titularidad del crédito, y ésta de forma transitoria, generalmente por un año, y no el ingreso tributario.

De todo esto habremos de colegir como este objetivo sólo podrá verse cubierto sobre la base de una estimación -valoración previa del «precio de la rentan- que marque ese límite e rentabilidad exigido y a partir del cual la renta sea pujada en Almoneda e indique las posibilidades de su recaudación ${ }^{10}$. Cuatro elementos lo hacen posible:

1- Individualización de la renta

2- Estimación de su valor

Cuaderno de 1462, disposición 44, p. 384.

" Como indica Menjot, citando a FAvier, para el caso local de Murcia, "para que este sistema de recaudación funcionara de manera adecuada, el precio del arrendamiento debía ser tal que la renta de la ciudad fuera lo más alta posible y que la ganancia del arrendador fuera suficientem. En Finanzas y fiscalidad concejiles ordinarias en Murcia en la Baja Edad Media, "Fiscalidad y Sociedad. Los murcianos y el impuesto en la Baja Edad Media». Ed. Academia Alfonso X el Sabio. Murcia, 1986. p. 69.

${ }^{9}$ No debemos dejar de lado que para el Rey «lo esencial era que sus numerosas rentas y los pesados impuestos que reclamaba fueran percibidos en el tiempo requerido y en las condiciones exigidas». Denis MENJOT, Aspectos de la Historia Urbana: la administración financiera y la contabilidad en Murcia en el siglo XV en «Fiscalidad y Sociedad», p.31.

1" Circunstancia ésta que Juan Antonio PARDOS MARTINEZ observa para el caso del Concejo de Burgos. La renta de la alcabala vieja, portazgo y barra... del concejo de Burgos durante el siglo XV (1492-1503), en "Historia de la Hacienda Española (Epocas Antigua y Medieval). Homenaje al profesor García de Valdeavellano». Instituto de Estudios Fiscales. Madrid 1982. pp. 653-654. 
3- Especificar los situados que sobre ésta se libran

4-Eliminar las posibles alteraciones sobre el valor de la renta.

\section{INDIVIDUALIZACIÓN DE LA RENTA}

Es sin duda un elemento a tener en cuenta. En puridad consiste en singularizar la renta a arrendar, acotarla, de manera tal que no se solapen, por confluencia, varias, circunstancia ésta que pasa por unificar rentas diversas asignándoles un único precio, lo que, sin duda alguna, atenta al interés de la propia Hacienda perturbando el objetivo arriba señalado, ya que individualizadas mantienen un valor que se anula al arrendarlas conjuntamente.

En este sentido la actuación pasa por ser doble:

1- Limitar temporalmente la misma renta.

2- Diferenciar distintas rentas que se arriendan de forma conjunta.

En el primer caso es el cuaderno de 1462 quien plantea el problema que se deriva para la Hacienda regia de un arrendamiento por un período superior a dos años ". Según éste, si el arrendamiento se establece por dos, tres, cuatro o más años, se entiende que durante este período y de forma anual la renta regresa - 'recuda' - al arrendador mayor "con maravedíes del año primero», es decir, con el precio fijado para el primer año, lo que evita el posible incremento anual del precio fijado según se puede esperar del rendimiento de la renta ${ }^{12}$. Y es que, tal como indica José Ruiz de Celada para el caso de las sisas en su memorial sobre el Estado de la bolsa de Valladolid ", este tipo de impuestos que gravan el consumo fluctúan de años de un gran rendimiento a otros de escasos beneficios, dependiendo en cualquier caso de la afluencia de mercaderes, de la producción o de los propios consumidores. Demasiadas variables como para que su rendimiento sea estable. El propio Ruiz de Celada indica, coincidiendo con los propios Cuadernos, que estos arrendamientos no deberían de exceder de dos años; espacio de tiempo que considera suficiente como para prever con ciertas probabilidades de acierto el precio de los productos, su afluencia e

1 A pesar de lo observado por LADERO QUESADA en su Fiscalidad regia y sector terciario en la Andalucia Bajomedieval, "Actas del II Coloquio de Historia Medieval Andaluzan, Sevilla 1982, al señalar que los arrendamientos se verificaban por varios años consecutivos, p. 14. No obstante PARDOS MARTínEZ indica lo poco habitual de estos arrendamientos bianuales. La renta de alcabala vieja... p. 669.

12 Cuaderno de 1462, disposición 163, p. 447.

13 José RUIZ DE CELADA, Estado de la bolsa de Valladolid. Examen de sus tributos, cargas y medios de su extinción. De su gobierno y reforma. Edición y estudio por Bartolomé YUN Casalilla. Valladolid, Secretariado de Publicaciones, Universidad, 1990. p. 266. 
incluso su consumo, lo que permitiría valorar acertadamente el valor de la alcabala a arrendar".

Pero la situación revierte en nueva desventaja para la Hacienda regia desde el momento que al arrendador se "le consiente faser e arrendar e abenir las rentas de los otros años que fincan del dicho arrendamiento", esto es, la capacidad de subrogar la actividad recaudatoria, o, de otra forma, subarrendar ésta en arrendadores menores. Y esto es así por cuanto el arrendador mayor, al "recudir» en él, y de forma anual, la renta, puede renovar períodicamente el precio del subarrendamiento, lo que va en claro detrimento de la Corona ya que no percibe beneficio alguno de esta circunstancia.

Para evitar este desajuste entre el precio fijado y el precio real de la renta se limita la capacidad arrendatoria de arrendadores y recaudadores mayores a tan sólo aquellos años en que «sea sacado recudimientos», en definitiva, aquel documento que permite el propio hecho recaudatorio. Se entiende que la 'carta de recabdacion' será la baza que el propio monarca jugará para garantizar un precio adecuado y revisable en aquellos arrendamientos prolongados, siendo la situación ideal el arrendamiento anual.

Las situaciones planteadas en los Cuadernos con respecto a la diversidad de rentas que se arriendan de forma conjunta dependerán del tipo de arrendamiento establecido, ya sean rentas que se arriendan por mayor, ya lo sean por menor. En cualquier caso, el perjuicio que puede ocasionarse en el interés de la Hacienda no reside en el precio del remate, por cuanto no se indica ilegalidad en el hecho de arrendar varias rentas, sino en la ocultación que se hace de la individualidad de cada una de ellas, lo que impide la realización de licitaciones o pujas por desconocer el precio sobre el que pujar cada renta. El temor real se observa nítidamente, se permite el arrendamiento conjunto, pero insistiendo en su diversidad. Se quiere evitar la unificación de distintas rentas por lo que de perjuicio supondría a sus intereses (el máximo beneficio del arrendamiento de sus rentas); no olvidemos el incremento sobre el precio inicialmente fijado que suponían las pujas realizadas tras el remate".

14 Pardos Martínez indica además como la administración mediante el arrendamiento salva «los problemas de alteraciones monetarias e inflación que caracterizaban al XV, al evolucionar los precios de arrendamiento a la par que los de bienes y dinero». La renta de la alcabala vieja... p. 619.

is $Y$ así, el cuaderno de 1484 en su disposición 119 , fol.66-67, señala: «E otrosy por quanto los arrendadores mayores y menores por faser algunas ynfintas y encubiertas en las nuestras rentas de algunas çibdades e villas e lugares arriendan dos rentas juntamente y un lugar con otro o parte de una renta con otra entera e por esta rasón no saben quanto esta cada renta sobre sy. E en caso de que algunos querían pujar alguna renta dellas porque les cunple la una renta y no la otra por rasón no la quieren ny pueden faser porque no saben sobre que contia an de arrendar o pujar». De igual forma aparece en el cuaderno de 1462, disposición 140, p. 434. 
Por todo ello se dispone que el arrendamiento de cada renta se haga de forma individualizada, dando posterior noticia a los contadores mayores o a sus lugartenientes de la cuantía del arrendamiento efectuado. Pero si aún así el arrendamiento se hiciera "ayuntado" se exige el repartimiento individualizado de cada renta, especificando en cada caso su precio, estableciéndose un plazo que en el caso de las rentas arrendadas 'por granado' es de un día para el cuaderno de 1462 y de cinco para el de $1484^{\text {" }}$, , siendo de 2 y 3 respectivamente para las que se arriendan 'por menudo' '. Repartimiento que había de efectuar el propio arrendador o bien, si así no fuera, el Contador Mayor para las primeras rentas y el Recaudador (1462) o el Juez de la ciudad, villa o lugar que fuera cabeza de partido (1484) para el segundo.

Pero el interés real por rentabilizar las rentas resaltando su individualidad se hace notable cuando los Cuadernos se refieren a las rentas arrendadas 'por menor'. En estos casos ambos Cuadernos se muestran más prolijos, ofreciendo una casuística que abunda en el deseo por diferenciar todos los miembros de rentas que en cada renta caben, ofreciendo la posibilidad de nuevas licitaciones que irían en beneficio del haber de la propia Hacienda. Y así partiendo del hecho de que quien arrendadara ciudad, villa o lugar (partidos menores) lo harán enteramente, esto es, incluyendo los «miembros de renta» que en cada caso cupieran (se entiende pues que la unidad básica de arrendamiento es la renta de estos partidos), plantean la posibilidad de que tales rentas no se quisieran coger enteramente, permitiéndose al Recaudador o Arrendador Mayor hacerlo. Es más, el Cuaderno de Enrique IV abre una nueva puerta al permitir al Arrendador Menor poner precio a cada una de las rentas que incluye su arrendamiento y rematarlas en almoneda. Se adivina la participación en el sistema de numerosos pequeños arrendatarios capaces de sostener rentas de escaso valor, lo que incrementaría por pujas los ingresos en el haber hacendísti$\mathrm{CO}^{18}$.

\section{ESTIMACIÓN DE SU VALOR}

Una vez individualizada la renta, se exige un conocimiento lo más exacto fol. 66

16 Cuaderno de 1462, disposición 139, p. 434. Cuaderno de 1484, disposición 118 , fol. 66-67.

"Cuaderno de 1462, disposición 140, p. 434. Cuaderno de 1484, disposición 119 ,

${ }_{18}$ Para la sociología de los arrendadores, aunque limitándose al caso de Murcia, ver Denis MENJOT, Finanzas y fiscalidad concejiles ordinarias en Murcia en la baja Edad Media, "Fiscalidad y Sociedad", pp. 74-75. 
posible de su rendimiento y, a partir de éste, deducir su valor, que servirá para establecer la base a partir de la cual efectuar las licitaciones en la almoneda ( «...puedan dar avisaçión para arrendar las dichas rentas de los años adelante venideros seguientes, segund cumple a mi serviçio "") y establecer un "mínimum", en caso de que el servicio recaudatorio se haga en régimen de contrato de recaudación, para que éste recoga en forma suficiente los créditos y derechos de la Hacienda regia. No debemos dejar de lado la utilidad de este conocimiento para la previsión de fondos en un futuro inmediato, adecuando su administración a las necesidades reales o del propio reino.

La labor previa de peritaje se realiza a través de dos mecanismos:

1 - «Faser y arrendan» por orden del Rey determinada renta.

2- Conocimiento de su valor a partir de las copias que desde los arrendadores y a través de los escribanos de rentas llegan a manos de los contadores mayores.

El primer mecanismo se aplica sobre aquellas rentas de las que se desconoce su rendimiento. Para estimar su valor el Rey, junto con los contadores mayores, envían a "faser» éstas a algunas ciudades, villas o lugares (presentándose estos partidos como campos de experimentación fiscal) a determinadas personas que, dada su acción recaudatoria, "faser», se les define como «fasedores" (bien es cierto que este término se presenta confuso al designar igualmente a aquellos lugartenientes de recaudadores y arrendadores que hacen efectiva la recaudación).

Una vez recaudada la renta el fasedor dará información de «lo que entienden que más podria valer» a los contadores mayores, pudiéndose arrendar a partir de este momento. Se especifica un plazo de treinta días desde aquel en que «fueren acabadas de faser las dichas rentas» para enviar la copia mencionada "l."

En el segundo mecanismo es el Escribano de las Rentas, como oficial de la administración, quien informa puntualmente del valor de las rentas. Y esto en dos momentos. Primero al dar noticia del remate establecido al ser los encargados de arrendar las rentas de aquellos partidos en los que es residente; más adelante -segundo momento-, tras el período de recaudación mediante la copia "signada e jurada» que ha de entregar a los contadores mayores y en la que se especifica su valor, circunstancia ésta posible al tener que efectuarse necesariamente toda labor recaudatoria ante su presencia.

Pero esta circunstancia no deja de tener un interés añadido, y es el hecho de reflejar esa primera titularidad del poder financiero en manos del Rey, quien a través de las Cortes negocia su capacidad de crear derecho tributario mediante

1") Cuaderno de 1462, disposición 150, p. 441.

2n Cuaderno de 1484, disposición 122, fol. 69. 
los Cuadernos de Alcabala. No olvidemos que esta labor pericial no haría sino responder a los deseos ya expresados por los monarcas en las Cortes de Madrigal de 1476. En éstas los procuradores manifiestan el deseo de que, siguiendo la costumbre instituida por Juan II, y muy relajada durante el reinado de Enrique IV, arrendadores y recaudadores dieran sus cuentas en forma «a los dichos contadores mayores de cuentas o en fin de cada un anno del tal recadimiento o arrendamiento, o a lo menos del terçio primero del ano seguiente" "'. Y así, en el cuaderno de 1484 , se establece como plazo para la entrega el mes de agosto de cada año prolongándose hasta noviembre si la renta "no fuere hecha»". Mientras no se entreguen no se darán las cartas de 'recudimiento' para el próximo período de recaudación. Siendo así, es de creer la diligencia en esta entrega por el perjuicio que en la labor recaudatoria produciría esta demora entre los arrendadores ${ }^{23}$.

De esta forma los contadores mayores son informados "por las dichas copias enteramente del valor de las dichas rentas», lo que les permite observar el posible desajuste entre el remate (valor supuesto) y el rendimiento real (valor cierto) de la renta arrendada, con lo que anualmente el remate se irá adecuando a las variaciones del rendimiento. Tampoco debemos dejar pasar por alto, abundando en lo antes citado, el hecho de que estas cuentas, tal y como señala el cuaderno de cortes de 1476, suponen un execelente medio por parte de la monarquía para conocer la propia hacienda ( el cuaderno señala como: «havían quedado grandes contías de mrs. de que nunca havían dado quita ni rraçon ${ }^{2} "$ ), permitiéndole percibir lo que en justicia le corresponde ("por que vuestra alteza pueda cobrar lo que justamente le es debido»), así como

2 C.L.C. p. 71. Petición 13. (Cortes de Madrigal de 1476).

2. Cuaderno de 1484, disposición 49, fol.11-12. También es recogida esta disposición en el Cuaderno de 1462, disposición 20, p. 387.

El hecho de no coincidir las fechas arriba señaladas con el período de recaudación (Enero-Enero) se puede deducir del hecho de ser en este caso el Escribano quien informe al Contador, actuando como intermediario entre Arrendador y Contador, con lo que la información necesariamente se retrasa al tener que recoger las cuentas de todos los arrendadores de su partido. En todo caso MENJOT cita la diversidad de años contables, La gestión de las Haciendas locales urbanas: el ejemplo de la ciudad de Murcia desde el año 1266 hasta mediados del siglo XV en «Fiscalidad y Sociedad», p. 89.

${ }^{23}$ Y así se señala en las Cortes de Madrigal, C.L.C. p. 71 petición 13: «...e no les eran dados los rrecudimientos por los contadores mayores, del anno venidero, fasta que havían dado sus quentas del anno pasado, según lo disponen las leyes de vuestros rreynos, de que se seguirá gran serviçio a vuestra alteza si así se hiçiese, e aun gran provecho a vuestros rreynos, porque los tales arrendadores e rrecaudadores, por poder dar sus quentas con tienpo, trabajarían por haver cartas de pago de lo que pagasen a los previllejos e libramientos para las pasar en quenta e pagarían los alcançes que vuestra alteza les hiçiese...»

${ }^{24}$ C.L.C. p.70. Petición 13 (Cortes de Madrial de 1476). 
organizarla y de esta forma poder situar privilegios y libramientos correctamente, de forma tal que sean satisfechos y no tornen en "albaquias".

Para asegurar la entrega de esta copia ambos cuadernos recurren a importantes medidas coercitivas: pérdida del oficio para el escribano y el pago de diferentes penas".

El detalle de la copia que ha de entregarse se hace evidente cuando los cuadernos se refieren a la actuación del fiel que, como cargo transitorio, cesa cuando aparece un arrendador ".. En este momento deberá entregar cuenta en la que se especifique todo lo que "montare e rendiere» la renta de la que fue fiel, detallándose "por menudo, buena e leal e verdadera syn arte e syn enganno, fasiendo sobre ello la sennal de la crus e los santos evangelios, nombrando el dia e la cosa e la persona o personas que la vendieren e compraren e el prefio de que resiben la dicha alcabala». Luego el conocimiento sobre el rendimiento y posibilidades de cada renta se presume minucioso y la copia una densa noticia de las compras, cambios, donaciones...que en el partido se realizaron durante el período de recaudación y sobre los que se efecutó la acción impositiva "’.

Pero la acción pericial rebasa la renta arrendada «por granado», deteniéndose con igual interés en las que se hacen «por menudo», siendo en estos casos el arrendador mayor, al subarrendar la función recaudatoria de aquellos "miembros de renta» que caben en la renta principal, quien informe de su valor. También, y como se podía observar para el caso anterior, la información abarca un segundo momento, esto es, el valor cierto tras el «acabamiento» de la recaudación ${ }^{2 k}$.

2s La pena para el escribano será del $1 \%$ ( «dies maravedíes al millar») «...de las dichas mis rentas ... que sobrello ante ellos pasaren». Cuaderno de 1462, disposición 20, p. 387. Cuaderno de 1484, disposición 49, fol. 11-12.

En cl caso de arrendadores, recaudadores, receptores o fasedores no sólo deberán arrendar tales rentas en presencia del dicho escribano, sino que incluso el hecho recaudatorio se desarrollará con su presencia, so pena de 5.000 mrs. por cada vez que así no lo hicieran. Y si la recaudación coincidiese con su ausencia, o bien ésta se efectuara en lugar donde no quisiera ir, cualquier escribano podrá dar fe de lo realizado, debiendo dar más tarde cumplida información al escribano de la renta para que pueda asentarlo en su registro ke lo ponga en tal copia de todas las otras rentas e posturas dellas». Ibidem.

26. Para el procedimiento recaudatorio en régimen de fieldad ver Denis MENJOT, $E l$ impuesto real en Murcia a principios del siglo XV: un caso de "práctica financiera" en "Fiscalidad y Sociedad", p. 144-147.

"La disposición hace referencia a la posibilidad de que una renta no sea contentada de fianzas, y ante la necesidad de subastarse de nuevo y con objeto de no dejar en suspensión la recaudación, ésta pasa a manos de fieles. Cuaderno de 1462, disposición 159, p. 444. Cuaderno de 1484, disposición 136, fols. 79-81.

:8 Cuaderno de 1462, disposición 130, p. 428. Cuaderno de 1484, disposición 112 , fols. 62-63. 
Visto el interés de la Hacienda por conocer el rendimiento de todas las rentas se puede deducir la posibilidad de un notable incremento de los ingresos procedentes de estas partidas, por lo que no ha de extrañar esta actitud vigilante ante sus rendimiento anuales intentando impedir que por desidia estos se vean menguados. No podemos tampoco dejar de lado el reconocimiento que la corona adquiere mediante este hecho de su poder fiscal, tal y como referíamos anteriormente, la obligación dada a los contadores en el cuaderno de 1484 por realizar una labor copilatoria con todas las copias referidas "." no es sino un deseo por parte de la Corona por manifestar esta capacidad.

\section{ESPECIFICAR LOS SITUADOS QUE SOBRE ÉSTA SE LIBRAN}

La sensibilidad de la Hacienda con respecto a este tema es especialmente importante; preocupación que se entiende lógica si consideramos los numerosos abusos que concurrían, tanto por parte de los beneficiarios por las cartas y albalaes de estos libramientos, como por parte de los arrendadores y recaudadores que son, a efectos, los que por libranza real ejecutan el pago dispuesto ".

Parece ser que hasta la redacción de estos cuadernos los libramientos se situaban sin considerar las posibilidades de la propia renta, lo que originaba grave quebranto en las arcas recaudatorias del arrendador que a la postre redundaba en "deserviçio" del rey por cuanto imposibilitaba al primero el poder contentar las rentas, es decir, no cubrir las pagas cuatrimestrales ya indicadas. Esta circunstancia se haría especialmente grave durante el reinado de Juan I quien, según el cuaderno de 1462, publicó una ley en la que se ordenaba el pago de todos los libramientos efectuados ". Los cuadernos, por tanto, no dejarán de reflejar un deseo real ya expresado previamente en Cortes. Y así, en las de Toledo de 1480, los monarcas manifiestan el gran detrimento del patrimonio real producto de la enajenación de las rentas durante el reinado de Enrique IV a causa de las «muchas e inmensas donaciones quel dicho sennor rey, nuestro hermano, fixo de muchos maravedís e pan e doblas e florines e sal e

29) *...un libro a su averiguaçión de sobre todos los partydos de las rentas de nuestro reyno de cada anno». Cuaderno de 1484, disposición 131, fol. 77.

*) No olvidemos que el más importante compromiso del arrendador consistía, además del pago del importe del precio de la renta, en satisfacer el salvado y situado que en ella hubiera. PARDOS MARTínez, La renta de la alcabala vieja... p. 656.

"Y además, hasta hacer efectivo el pago de los mencionados libramientos, recaudaores y arrendadores "eran presos e prendados», lo que resulta manifiesta injusticia. Cuaderno de 1462, disposición 144, p. 437. 
ganado, e otras cosas delas sus alcavalas e tercias e diezmos e aduanas e almoxarifadgos e salinas e servicio e montadgos ""); se entiende el deseo de la corona de revertir a sus arcas el monto de esas rentas, esto es, recomponer su capacidad financiera ".

Esta reorganización se verificará en los Libros de las relaciones, habiéndose exigido previamente (Cortes de 1476, 1480) que todas estas mercedes y privilegios situados sobre las rentas reales sean sobreescritos y revisados en sus condiciones '; ordenándose que su confirmación venga por parte de los Contadores mayores, circunstancia ésta a la que se refieren los cuadernos al señalar la manifiesta irregularidad en la que cartas, sobrecartas y albalaes librados «sobre los maravedíes y otras cosas tocantes a mi fasienda e rentas" caen al no encontrarse confirmadas por los susodichos ". Y es que de no ser así, de no revisarse el situado, las rentas y recaudaciones se «enbaraçan» presionando de tal forma sobre arrendadores y recaudadores que no pueden equilibrar la recaudación con la libranza a efectuar.

La actuación frente a esta evidente arbitrariedad pasa por la derogación de leyes como la ya citada, la no aceptación de más libramiento de los que caben en cada renta y la necesaria confirmación de los contadores mayores para poder colocar cartas, sobrecartas y albalaes sobre las rentas ${ }^{* 6}$.

Los objetivos que mediante estas medidas se pretende cubrir pasan por ser dos:

32 C.L.C. p.166. Petición 86 (Cortes de Toledo de 1480).

"En este aspecto RuCQuOI señala, citando a MATilla TASCón, que las Cortes de Toledo suponen "éste último proceso de control» de los recursos financieros de la Corona limitando las exenciones y enajenaciones [ $L a$ enajenación de las rentas reales: el caso de Valladolid en los siglos XIII a XV en «Historia de la Hacienda Española (épocas Antigua y Medieval)]. Homenaje al profesor García de Valdeavellano». Instituto de Estudios Fiscales. Madrid, 1982. pp. 801-802.

i No obstante habrá que incidir en la posibilidad de que tales situados no sólo respondan a un carácter de merced y privilegio, sino también como garantia de operaciones de endeudamiento contraídas por la Corona, tal y como observa PARDOS MARTíneZ para la alcabala vieja y nueva refiriéndose al caso local del concejo de Burgos. La renta de la alcabala vieja... pp. 621 y 651 .

is Cuaderno de 1462, disposición 166, pag. 448. Cuaderno de 1484, disposición 138, fol. 82.

Confirmación que debía de partir de los contadores a cuyo cargo se encontraba el Oficio de relaciones, quienes se encargaban de entregar a arrendadores, recaudadores 0 tesoreros un documento en el que constaba el «situado y salvado» que gravaba la renta para que procedieran a su pago. LADERO QUESADA, La Hacienda Real de Castilla en el siglo XV p. 19.

${ }^{36}$ En el cuaderno de 1484, disposición 139, fol. 83, se añade que en todas las cosas referentes a la «hacienda y renta» se deberá cumplir la ley que Enrique IV promulgó en la villa de Aranda en 1461. 
1- Evitar el desaliento entre los posibles licitadores (a la postre futuros arrendadores) quienes al observar un desequilibrio desfavorable entre la recaudación efectiva y la situada no pujarían en almoneda.

2- El propio monarca efectuará paralelamente una minuciosa revisión de rodos los libramientos, situados y salvados hasta ese momento realizados, los cuales menguan el rendimiento de las rentas mermando la propia Hacienda real.

Pero, a la inversa, los mismos arrendadores y recaudadores pueden negarse a recibir libranzas legalmente estableceidas al asegurar que tales situados no caben en sus rentas. Como se puede observar la posibilidad abierta incidiría en notables abusos, por lo que, a efectos de solventarlos se obliga a ambos a efectuar juramento en el que afirmen lo ya indicado. Juramento que se deberá entregar de "por fe» a los contadores mayores para que así se disponga el "recabdimyento "». Tal disposición no haría sino recoger lo ya dispuesto en las Cortes de Madrigal de 1476, en donde se reconoce a los titulares de privilegios situados la capacidad para cobrar sus créditos, pudiendo requerir al concejo y justicia de la ciudad, villa o lugar donde se hayan situadas estas mercedes de maravedíes para que, en caso de difultades en el cobro dispuesto, juzguen en su favor. ${ }^{\text {to }}$

No obstante, y a pesar del carácter probatorio de la palabra dada bajo juramento y del incesante recuerdo que en ambos cuadernos se hace sobre las penas de perjurio, los abusos persistieron. Así se desprende de la propia lectura de los textos, máxime cuando el cuaderno de 1484 establece un nuevo mecanismo que se perfila como definitivo. Según éste, después que las rentas de cualquier partido fueran arrendadas y rematadas por los contadores mayores en el estrado de las rentas harán cuenta con los arrendadores y recaudadores mayores para librar los maravedíes correspondientes en el dicho «recabdymientom. Esta cuenta se efectuará del siguiente modo:

"Cuaderno de 1462, disposición 156, p. 443. En el cuaderno de 1484, disposición 134 , fol. 79 , se especifica además que el «escrivano sea thenido de tomar el dicho juramento a los dichos nuestros recabdadores y darlo por fe a los dichos nuestros contadores mayores para que asy se ponga en el recadimyento so pena de dos mill maravedíes para la nuestra cámaran.

8 «E sy non lo hizieren asy, que rrequieran al conçejo e justiçia de la tal çibdad o villa o logar para que le hagan luego administrar justiçia; e sy lo assy no hizieren que las tales personas vengan o enbien al nuestro Consejo e muestren las dichas diligençias e que con ellas les sea dado executor tal como por vuestra petiçión lo pedís para que pueda hazer execuçión por la tal deuda en los bienes e personas de los deudores e de sus fiadores e de las justiçias e rregidores e offiçiales del conçejo que fueron rrequeridos e fueron nigligentes en lo cunplir, e que de otra quissa no se haga so las penas contenidas en vuestra petiçión» C.L.C. p. 11. Petición 2 (Cortes de Madrigal de 1476). 
En el cargo, y por suspensión, se colocará el situado y salvado "que estovyere sacado en los nuestros libros de las relaciones» así como el "prometydo que estovyere ganado en las dichas rentas", añadiendo por último cualquier suspensión que según las condiciones del arrendamiento se hubieran de «suspender». Una vez hallada la diferencia lo que quede líquido y «averiguado» se librará como beneficio en los arrendadores y recaudadores mayores de cada partido. De esta forma se colige que estos arrendadores y recaudadores podrán pagar «a las personas que en ellos fueren lybrados...a los plasos y en la manera que fueren oblygados» por cuanto (y de aquí estas previsiones) los cargos en ningún caso podrán sobrepasar el haber recaudatorio ".

Es de creer al respecto que la propia Hacienda recoja la pretensión señalada en las Cortes de Toledo de 1480 en el sentido de nombrar de forma explícita aquellas rentas susceptibles de recibir situados, impidiéndose que estos se puedan "mudar» a otras rentas *". Sobra decir que tales situados se colocarán sobre aquellas rentas con suficiente "cabimiento", dado el propio interés real en las Cortes de 1476 por satisfacer las deudas contraídas por privilegios otorgados".

Por último, el cargo, averiguado de la forma ya indicada, se asentará en los Libros de las relaciones de los contadores mayores, firmado por el arrendador 0 recaudador correspondiente, disponiendo éstos de una copia «porque sepan lo que en ellos ha de ser librados», lo que no dejará de incidir en ese interés real por reorganizar la Hacienda.

\section{ELIMINAR LAS POSIBLES ALTERACIONES SOBRE EL VALOR DE LA RENTA}

Un último elemento a la hora de considerar el precio de la renta es el de soslayar todas aquellas «infyntas y colusiones» que menguan su valor, ya sea al acceder a su arrendamiento por precios muy bajos, ya mediante las tomas 0 embargos que pueden realizarse sobre los maravedíes de la renta arrendada ${ }^{42}$. El quebranto que esto supone a la Hacienda Real y a la propia recaudación es evidente, a la par que retrae las licitaciones y por tanto atenta al propio sistema de arrendamiento. Basta por tanto referirse al objetivo expresado en las Cortes de Toledo de 1480 cuando señala: «...reintegrar el dicho patrimonio real e

19 Cuaderno de 1484, disposición 127, fols. 72-75.

* C.L.C. pags. 181 y 182. Petición 104 (Cortes de Toledo de 1480).

4 C.L.C. pag. 71. Petición 13 (Cortes de Madrigal de 1476).

${ }^{42}$ Cuaderno de 1462, disposición 101, p. 414. Cuaderno de 1484, disposición 89, fol. 46. 
rentas del, por manera que con ellos pudiessemos sostener nuestro real estado e mantener nuestros reynos en justicia... "", para que no extrañe el interés de ambos cuadernos por limitar estas actuaciones.

En ambos casos, la acción delictiva puede haber sido desarrollada según ambos cuadernos por grandes del reino, prelados, maestres, duques, condes, marqueses, ricos hombres, priores, comendadores, así como por concejos y universidades, particularmente alcaldes, alguaciles y regidores. En general, aquellas personas o instituciones con suficiente capacidad coactiva como para realizar algún tipo de arbitrariedad.

Dos son los tipos de acciones punibles en los que más insisten ambos cuadernos:

1 - No dejando "faser e arrendar las dichas mis rentas libres e desembargadamente», haciendo alguna "toma» sobre los maravedíes de dichas rentas, o bien embargando alguna cuenta; actuaciones todas éstas por los que deberán responder mediante diversas medidas coercitivas:

* Pagando las «protestaciones» que los arrendadores solicitaran por dicho agravio.

* Vendiendo cualquier maravedí de juro de heredad "que tuvieran en los mis libros" para pagar las tomas efectuadas al arrendador ". Y si se careciera de éstos, se procederá al embargo y subasta de sus bienes, ya sean muebles, raíces o semovientes".

2- En otros casos, no obstante, estas tomas y embargos se hacen efectivos sobre sus lugares de solariego o encomiendas, haciendo uso, por tanto, de prerrogativas jurisdiccionales que atentan de hecho a la labor recaudatoria de los arrendadores. Cuando concurre esta circunstancia la Hacienda regia no intenta pertubar esta acción, lo que pasaría por clara injerencia, sino que se limita a recordar a éstos la necesidad de dar testimonio de estas tomas y embargos para que los arrendadores puedan presentarlas a los contadores mayores «e les sean resçibidos en cuenta de los dichos sus cargos», pues sólo de esta forma se justifica la imposibilidad de hacer efectivas las cuotas tributarias dado el desequilibrio que se produce en la balanza contable entre los cargos y la data, ya que, de no ser de este modo, se deduce que el arrendador habría de

"C.L.C. p. 168. Petición 86 (Cortes de Toledo de 1480).

4 RUCQUOI señala, para el caso de Valladolid, la abundancia de juros, situados preferentemente sobre las rentas del vino, carne y pescado, madera, fruta y hortalizas - «los productos de mayor rendimiento"-, incidiendo en su carácter de mercedes regias. La enajenación de las rentas reales... pp. 814-815. La posibilidad de enajenarlos se enmarcaría dentro del proyecto de reorganización de los recursos financieros de la Corona que culmina en las Cortes de 1480 . Ver nota 33. fol.46

1) Cuaderno de 1462, disposición 101, p.414. Cuaderno de 1484, disposición 89, 
asumir la responsabilidad del déficit, lo que, sin duda alguna, propicia las quiebras y desalienta, como ya mencionaba arriba, futuras licitaciones *. Además conocidas estas tomas, antes del fin del período recaudatorio, la Hacienda podría replantear sus actuaciones toda vez que se intuía el monto de las quiebras.

Para garantizar este testimonio, y si coincidiera que estos caballeros y prelados se negaran a darlo, se obliga en su lugar al concejo, regidores y justicias del lugar a ofrecerlo, y si tampoco accedieran, que cualquier justicia real ejecute, ante la simple querella del arrendador, en cualuier vecino y morador de dicho lugar sobre sus "bienes e ganados e mercadorias" por la cuantía de tal toma o embargo.

También insiste el Cuaderno de 1462 en la imposibilidad de estas personas con capacidad jurisdiccional a acceder al arrendamiento de las rentas de dichos lugares, exigiéndoles juramento y «pleito homenaje» al efecto; es más, se les pide "todo favor e ayuda " a los arrendadores y recaudadores de éstas so pena en cualquier caso de la protestación que contra ellos hicieran estos últimos y la confiscación "para la mi cámara y fisco" de todos sus bienes muebles y raíces". De igual foma intenta disuadirles de encargar su arrendamiento a personas ajenas, o bien que éstos «les consintieren levar los dichos provechos e ynteresese fisieran en ellas otro fraudes e colasiones algunas», condenando a muerte a quien accediera a dicha acción y entregando al perjudicado aquellos maravedíes de juro de heredad y otros situados que estos caballeros y prelados poseyeran.

Por último este "menguamiento" puede afectar a aquellas rentas que se «fasen» por menor. Según dicta el Cuaderno de 1484 ciertos arrendadores mayores llegan a exigir de forma oculta un precio mayor al real, lo que puede suponer algunos maravedíes de más sobre cada millar "y algunas gallynas e otras cosas", lo cual va en detrimento de la Hacienda por doble motivo:

* Se retraen las licitaciones ante el evidente abuso.

* La propia Hacienda deja de percibir unos beneficios que, al no referirse en las copias que se envían a los contadores, se escapan de forma fraudulenta. fol.48

${ }^{46}$ Cuaderno de 1462, disposición 102, p.416. Cuaderno de 1484, disposición 90,

47 En concreto se indica que los dichos caballeros y personas, al tiempo que se presentaran las cartas de recudimientos de tales partidos «e treynta dias despues» estarán obligados a presentarse por si o por sus procuradores en los concejos y ayuntamiento de tales ciudades y villas y hagan juramento y pleito homenaje de no arrendar por si ni por otros las alcabalas y tercias de tales ciudades, villas o lugares «nin levar dellas e por ellas equivalençia táçita nin espresamente serviçio nyn ynterese nin otra cosa alguna" (Cuaderno de 1462, disposición 118, p. 422). 
Las medidas que intentan evitar este hecho tienden a definir el precio de forma clara "sin tener cosa secreta para sy" "'.

Como se puede advertir, el interés real se centra en potenciar el propio sistema de arrendamiento sobre la base de asegurar a los posibles arrendadores la imposibilidad de arbitrariedades que impidan el libre ejercicio de su función recaudatoria y reste beneficio al rendimiento de la propia renta.

\section{RÉSUMÉ}

J'ai prétendu, dans ce travail, étudier la gestion fiscale des Finances Royales pendant la seconde moitié du XV ${ }^{\mathrm{cm}}$ siècle, à travers son impôt le plus significatif: limpôt sur les ventes.

J'ai eu recours pour cela à la confrontation des deux cahiers de l'Impôt sur les Ventes les plus systématisés pendant ce siècle, celui de 1462 rédigé pendant le règne d'Enrique IV et celui de 1484, rédigé pendant le règne des Rois Catholiques. A travers ces textes, nous pouvons déduire comment l'impôt sur les ventes se présente à nous, d'un point de vue juridique, comme un impôt indirect, puisque les Finances Royales perçoivent des sommes tributaires de personnes distinctes de celles que la loi taxe, c'est à dire, à travers le système de fermage. Ceci nous permet d'élucider la double qualification (le double titre) du pouvoir financier: Le Roi, sujet actif de l'imposition. Le Fermier, sujet actif de la relation tributaire.

La relation qui s'établit entre les deux se règle aux Cortes et à travers les Cahiers de l'Impôt sur les Ventes (ce qui m'a mène à réaliser une brève étude comparative de chacun d'eux). Et bien que le système supposa clairement une perte pour le Roi dans la gestion tributaire de l'impôt, il articula cependant clairement toutes les mesures qui lui permettraient de rentabiliser en termes d'intérêts économiques, la perte de cette capacité administrative dans la gestion de la perception de l'impôt sur les ventes. Elles furent articulées tout autour de ce que i'appelle: «la valoration préalable du prix du recouvrement» qui se présente comme étant la ligne maîtresse de l'article.

\section{SUMMARY}

I have tried in this work to study the fiscal management of the Royal Finances during the second half of the $\mathrm{XV}$ ih century through its most significative tax: tax on sales.

Therefor, I confronted the two most systematized Tax on Sales Registers during that century, one of 1462 redacted during the reign of Enrique IV and one of 1484,

* Cuaderno de 1484, disposición 82, fols. 35-37. 
redacted during the reign of the Catholic Kings. Through those texts, we can deduct how the tax on sales was presented, from a juridical point of view, as an indirect tax, since the Royal Finances collected tributary amounts of money from people who wrere in fact not the ones that the law mentioned, which is, through the renting system. This allows us to clarify a double qualification of the financial power: The King, active subject of the tax system. The Farmer, active subject of the tributary relation.

The relation established between both is regulated by the Spanish Parliament through Tax on Sales Registers (which brings me to realize a short comparative study of each of them).

Though the system supposed clearly a loss for the King in his tributary management of taxes, it articulates nevertheless all the measures that woud allow him to make profitable, as far as economic interests are concerned, the loss of this administrative capacity in managing the tax on sales collection. They were articulated all around what I would call "the previous valorization of the cost of revenues", which is in fact the key line of the article. 